\title{
Modeling the Effect of Oil Price on Global Fertilizer Prices*
}

\author{
Ping-Yu Chen \\ Department of Applied Economics \\ National Chung Hsing University \\ Taichung, Taiwan \\ Chia-Lin Chang \\ Department of Applied Economics \\ National Chung Hsing University \\ Taichung, Taiwan \\ Chi-Chung Chen \\ Department of Applied Economics \\ National Chung Hsing University \\ Taichung, Taiwan \\ Michael McAleer \\ Econometric Institute \\ Erasmus School of Economics \\ Erasmus University Rotterdam \\ and \\ Tinbergen Institute \\ The Netherlands \\ and \\ Institute of Economic Research \\ Kyoto University \\ Japan \\ EI 2010-56
}

Revised: September 2010

* The authors wish to acknowledge the financial support of the National Research Council, Taiwan. The fourth author would also like to acknowledge the financial support of the Australian Research Council and the Japan Society for the Promotion of Science. This paper is a substantially revised version of "Modelling the Volatility in Global Fertilizer Prices". 


\begin{abstract}
The main purpose of this paper is to evaluate the effect of crude oil price on global fertilizer prices in both the mean and volatility. The endogenous structural breakpoint unit root test, the autoregressive distributed lag (ARDL) model, and alternative volatility models, including the generalized autoregressive conditional heteroskedasticity (GARCH) model, Exponential GARCH (EGARCH) model, and GJR model, are used to investigate the relationship between crude oil price and six global fertilizer prices. Weekly data for 2003-2008 for the seven price series are analyzed. The empirical results from ARDL show that most fertilizer prices are significantly affected by the crude oil price, which explains why global fertilizer prices reached a peak in 2008. We also find that that the volatility of global fertilizer prices and crude oil price from March to December 2008 are higher than in other periods, and that the peak crude oil price caused greater volatility in the crude oil price and global fertilizer prices. As volatility invokes financial risk, the relationship between oil price and global fertilizer prices and their associated volatility is important for public policy relating to the development of optimal energy use, global agricultural production, and financial integration.
\end{abstract}

Key words: Volatility, Global fertilizer price, Crude oil price, Non-renewable fertilizers, Structural breakpoint unit root test. 


\section{Introduction}

The world population in 2000 was more than 6 billion, and is expected to reach 8 billion in 2025, based on projections by United Nation Population Division. The increase in global population, combined with economic development, will place increasing demand on agricultural food products, especially grains, rice, soybeans, and sugarcane. The derived demand for energy crops has been increased significantly due to the development of bio-fuel. Such development can lead to food shortages and increasing international food prices, which will encourage farmers to expand planted acreage. This predicament has increased the derived demand for global fertilizers and increased fertilizer prices.

Fertilizers are combinations of nutrients that enable plants to grow. The essential elements of fertilizers are nitrogen, phosphorus, and potassium. Urea fertilizer is the major fertilizer that provides the element of nitrogen, and is produced through converting atmospheric nitrogen using natural gas. Ammonia and phosphoric acid (hereafter ACID) are also produced using energy. Thus, prices for urea, ammonia, and ACID will be affected by energy prices. Monoammonium phosphate (hereafter MAP) and muriate of potash (hereafter MOP) are two other important fertilizers that are sources of phosphorus and potassium. As most of the world's phosphate for fertilizer is mined, and hence is non-renewable, over the last decade the prices of phosphate and potash fertilizers have risen more steeply than the price of nitrogen-based urea.

Figure 1 shows the trends in six fertilizer prices and Dubai crude oil price during the period 2003-2008. It is clear that most of these prices changed dramatically in 2007 and 2008. Figure 2 shows the trends in the prices of the main fertilizers, including MAP, MOP and urea, and Dubai crude oil weekly prices, from 2003-2008. This figure shows that fertilizers and Dubai crude oil price exhibit positive trends. Moreover, MAP and 
MOP prices had upsurge in early 2008. These figures show there is a clear positive relationship between global fertilizer prices and crude oil price. The purpose of this paper is to investigate the relationship between crude oil price and global fertilizer prices, in both the mean and volatility. As volatility invokes financial risk, such empirical results should provide useful information regarding the risks associated with variations in global fertilizer prices due to variations in oil price, with significant implications for optimal energy use, global agricultural production, and financial integration.

The remainder of the paper is organized as follows. Section 2 introduces the data, the empirical models are discussed in Section 3, and the empirical results are analyzed in Section 4. Some concluding remarks related to the energy policy implications of the volatility of global fertilizer prices are given in the final section.

\section{Data}

The source of the data is divided into two parts. The weekly global fertilizer supply prices are obtained from the Fertilizer Market Bulletin (hereafter FMB) weekly fertilizer report, while the weekly Dubai crude oil prices are obtained from the database in the Bureau of Energy during the period 2003-2008. Table 1 gives the descriptive statistics of six fertilizer prices, including MAP, urea, ammonia, ACID, phosphate rock (hereafter ROCK), and MOP, and Dubai crude oil prices. The MAP prices show a steady upward trend, but have a sharp price spike in February 2008, as shown in Figure 1. The prices of urea and ammonia vary considerably, with steady increases over time. The ACID, ROCK, and MOP supply prices do not fluctuate significantly, but generally have upward trends. The trend in crude oil prices is relatively stable.

\section{Model Specifications}


Both the autoregressive distributed lag (ARDL) model and the generalized autoregressive conditional heteroskedasticity $(\mathrm{GARCH})$ model will be used to evaluate the effects of oil and global fertilizer prices, and to model the volatility in global fertilizer and crude oil prices. Before estimating the ARDL and GARCH models, the Lee and Strazicich [1] approach will be used to capture the structural breakpoint in fertilizer prices, which should enable identification of alternative time periods for the volatility in fertilizer prices.

\subsection{Minimum LM unit root test with two endogenous breaks}

Most traditional empirical studies use regression methods to estimate relationships among variables under the assumption of stationarity. However, spurious regression results may arise when some or all of the variables are non-stationary. The Dickey-Fuller [2, 3] test, Augmented Dickey-Fuller (ADF) test [4], and Phillips-Perron test [5] are widely-used unit root tests, but they are based on data generation processes with no structural breaks. Ignoring possible structural breaks can lead to non-rejection of the null hypothesis of non-stationarity, so that the effects of structural breaks may be attributed to the existence of a unit root. Nelson and Plosser [6] used the Dickey-Fuller unit root test to examine U.S. macroeconomic time series, and found that widespread non-stationarity.

In order to tackle the problem of structural breaks, Perron [7] proposed a unit root test with a structural breakpoint, which used an exogenous structural break to re-examine Nelson and Plosser's [6] data. The empirical results showed that most macroeconomic time series do not have unit roots, and the data features displayed by variables with a structural change are similar to those displayed by variables with unit roots. Thus, it is important to test for structural changes, otherwise an incorrect outcome of the unit root test is likely.

Banerjee et al. [8] and Zivot and Andrews [9] modified the unit root test with a 
known breakpoint to a unit root test with an unknown breakpoint. Lumsdaine and Papell [10] and Lee and Strazicich [1] transformed the unit root test with an unknown breakpoint into a unit root test with two unknown breakpoints. However, Lee and Strazicich [1] establish minimum LM unit root test with two unknown structural change points to compensate for the shortcomings of the test. Both the null and alternative hypotheses are specified for series with two endogenous structural breakpoints.

\subsection{Autoregressive Distributed Lag Model}

Fertilizer can be divided into organic fertilizer and chemical fertilizer, with the latter being a high user of energy. For instance, nitrogen fertilizer production relies mainly on coal and natural gas, so that a causal relationship might be deemed to exist between crude oil and fertilizers¥ prices. Such a relationship may be determined by a Granger Causality test and the autoregressive distributed lag (hereafter ARDL) model. The ARDL model, in which the data determine the short-run dynamics, would seem to be one of the most widely used models for estimating time series energy demand relationships. For instance, Jones [11], and Benten and Engsted [12], used the ARDL model to investigate a demand relationship for U.S. petroleum consumption and Danish residential energy consumption. Furthermore, Dimitropoulos et al. [13], Hunt et al. [14], and Hunt and Ninomiya [15] used the ARDL model to examine various energy demand models.

The ARDL model combines dynamics and interdependence with different interpretations based on linear relationships [16]. In the model, the price of a specific fertilizer is explained by lags of its own price and the lagged values of the oil price. A general ARDL model for the global fertilizer price can be written as:

FertilizerP $_{t}=\alpha_{0}+\sum_{i=1}^{p} \alpha_{i}$ FertilizerP $_{t-i}+\sum_{j=1}^{q} \beta_{j}$ OilP $_{t-j}+u_{t}$

where Fertilizer $P_{t}$ denotes the global fertilizer price at time $t$, and $O i l P_{t}$ is the price of 
crude oil at time t.

The coefficient $\beta_{j}$ is the effect of the $j$-period lagged crude oil price on the fertilizer price, which means that the fertilizer price can be predicted by the crude oil price. A test of the null hypothesis that each $\beta_{j}=0$ is a test of Granger non-causality.

All the variables included in the price should be stationary series to avoid spurious regression results, whereby the asymptotic standard normal results no longer hold. For this reason, the structural breakpoints of the crude oil price are estimated using the two-break minimum Lagrange Multiplier (LM) unit root test of Lee and Strazicich (2003). If and when the appropriate structural breakpoints are found, the fertilizer price equations will be estimated for different periods.

\subsection{Conditional Mean and Conditional Volatility Models}

Engle [17] captured time-varying conditional volatility, or financial risk, through the autoregressive conditional heteroskedasticity (ARCH) model. Subsequent extensions, such as the generalized ARCH (GARCH) model of Bollerslev [18], have been used to capture dynamic volatility for univariate and multivariate processes. The GARCH model is most widely used for symmetric shocks. In the presence of asymmetric shocks, whereby positive and negative shocks of equal magnitude have different impacts on volatility, the GJR model of Glosten et al. [19] and the EGARCH model of Nelson [20] are very useful. Further theoretical developments in specification, estimation and asymptotic theory have been suggested in Ling and Li [21], Ling and McAleer [22, 23, 24, 25], and McAleer [26].

The following model and discussion are based on McAleer [26] and McAleer et al. [27]. The methods have been extended detect the volatility in patent growth [28], in analyzing the volatility of USA ecological patents $[29,30]$, in modelling the volatility of environment risk [31], and the volatility of atmospheric carbon dioxide 
concentrations [32]. However, there does not yet seem to have been any empirical analysis of such volatility models on global fertilizer prices, and hence no assessment of risk associated with such prices.

In this paper, we consider the stationary $\operatorname{AR}(1)-\operatorname{GARCH}(1,1)$, or $\operatorname{ARMA}(\mathrm{p}, \mathrm{q})-\mathrm{GARCH}(1,1)$, model for the global fertilizer price series data, namely $y_{t}$ :

$$
\begin{aligned}
& y_{t}=\phi_{1}+\phi_{2} y_{t-1}+\varepsilon_{t}, \quad \text { for } t=1, \ldots, n, \\
& y_{t}=A R M A(p, q)+\varepsilon_{t}
\end{aligned}
$$

where $\varepsilon_{t}$ is the unconditional shock (or movement in global fertilizer prices), and is given by:

$$
\begin{aligned}
& \varepsilon_{t}=\eta_{t} \sqrt{h_{t}}, \eta_{t} \sim \operatorname{iid}(0,1), \\
& h_{t}=\omega+\alpha \varepsilon_{t-1}^{2}+\beta h_{t-1},
\end{aligned}
$$

and $\omega \geq 0, \alpha \geq 0, \beta \geq 0$ are sufficient conditions to ensure that the conditional variance $h_{t} \geq 0$. Ling and McAleer [25] indicated equation (2) in the AR(1) process could be modified to incorporate a non-stationary $\operatorname{ARMA}(p, q)$ conditional mean and a stationary GARCH(r,s) conditional variance. In (2), the $\alpha$ (or $\mathrm{ARCH}$ ) effect indicates the short run persistence of shocks, while the $\beta$ (or GARCH) effect indicates the contribution of shocks to long run persistence (namely, $\alpha+\beta$ ).

The parameters in equations (1) and (2) are typically estimated by the maximum likelihood method. Ling and McAleer [25] investigate the properties of adaptive estimators for univariate non-stationary ARMA models with GARCH(r,s) errors. The conditional log-likelihood function is given as follows:

$$
\sum_{t=1}^{n} l_{t}=-\frac{1}{2} \sum_{t=1}^{n}\left(\log h_{t}+\frac{\varepsilon_{t}^{2}}{h_{t}}\right)
$$

As the GARCH process in equation (2) is a function of the unconditional shocks, the moments of $\varepsilon_{t}$ need to be investigated. Ling and Li [22] showed that the $\operatorname{ARCH}(\mathrm{p}, \mathrm{q})$ model is strictly stationary and ergodic if the second moment is finite, that is, 
$(\alpha+\beta)^{2}+2 \alpha^{2}<1$. Ling and McAleer [24] showed that the Quasi MLE (QMLE) for $\operatorname{GARCH}(p, q)$ is consistent if the second moment is finite. Ling and $\mathrm{Li}$ [21] demonstrated that the local QMLE is asymptotically normal if the fourth moment is finite, that is, $E\left(\varepsilon_{t}^{4}<\infty\right)$, while Ling and McAleer [24] proved that the global QMLE is asymptotically normal if the sixth moment is finite, that is, $E\left(\varepsilon_{t}^{6}<\infty\right)$. Using results from Ling and Li [21] and Ling and McAleer [22, 23] (see also [18] and [33]), the necessary and sufficient condition for the existence of the second moment of $\varepsilon_{t}$ for $\operatorname{GARCH}(1,1)$ is $\alpha+\beta<1$ and, under normality, the necessary and sufficient condition for the existence of the fourth moment is $(\alpha+\beta)^{2}+2 \alpha^{2}<1$.

For the univariate $\operatorname{GARCH}(\mathrm{p}, \mathrm{q})$ model, several regularity conditions exist that enable the statistical validity of the model to be checked against the empirical data. Bougerol and Picard [34] derived the necessary and sufficient condition, namely the log-moment condition or the negativity of a Lyapunov exponent, for strict stationarity and ergodicity (see also [33]). Using the log-moment condition, Elie and Jeantheau [35] and Jeantheau [36] established it was sufficient for consistency of the QMLE of $\operatorname{GARCH}(p, q)$ (see [37] for the proof in the case of $\operatorname{GARCH}(1,1))$, and Boussama [38] showed that it was sufficient for asymptotic normality. Based on these theoretical developments, a sufficient condition for the QMLE of $\operatorname{GARCH}(1,1)$ to be consistent and asymptotically normal is given by the log-moment condition, namely

$$
E\left(\log \left(\alpha \eta_{t}^{2}+\beta\right)\right)<0
$$

However, this condition is not straightforward to check in practice, even for the $\operatorname{GARCH}(1,1)$ model, as it involves the expectation of a function of a random variable and unknown parameters. The extension of the log-moment condition to multivariate $\operatorname{GARCH}(p, q)$ models has not yet been shown to exist, although Jeantheau [36] showed that the ultivariate log-moment condition could be verified under the additional 
assumption that the determinant of the unconditional variance of $\varepsilon_{t}$ in (1) is finite. Jeantheau [36] assumed a multivariate log-moment condition to prove consistency of the QMLE of the multivariate GARCH(p,q) model. An extension of Boussama's [38] log-moment condition to prove the asymptotic normality of the QMLE of the multivariate $\operatorname{GARCH}(\mathrm{p}, \mathrm{q})$ process is not yet available.

The effects of positive shocks on the conditional variance, $h_{t}$, are assumed to be the same as the negative shocks in the symmetric GARCH model. In order to accommodate asymmetric behavior, Glosten et al. [19] proposed the GJR model, for which GJR(1,1) is defined as follows:

$$
h_{t}=\omega+\left(\alpha+\gamma I\left(\eta_{t-1}\right)\right) \varepsilon_{t-1}^{2}+\beta h_{t-1}
$$

where $\omega>0, \alpha \geq 0, \alpha+\gamma \geq 0, \beta \geq 0$ are sufficient conditions for $h_{t}>0$ and $I\left(\eta_{t}\right)$ is an indicator variable defined by

$$
I\left(\eta_{t}\right)= \begin{cases}1 & \varepsilon_{t}<0 \\ 0 & \varepsilon_{t} \geq 0\end{cases}
$$

as $\eta_{t}$ has the same sign as $\varepsilon_{t}$. The indicator variable differentiates between positive and negative shocks, so that asymmetric effects in the data are captured by the coefficient $\gamma$, with $\gamma \geq 0$. The asymmetric effect, $\gamma$, measures the contribution of shocks to both short run persistence, $\alpha+\gamma / 2$, and to long run persistence, $\alpha+\beta+\gamma / 2$.

Ling and McAleer [23] derived the unique strictly stationary and ergodic solution of a family of GARCH processes, which includes GJR(1,1) as a special case, a simple sufficient condition for the existence of the solution, and the necessary and sufficient condition for the existence of the moments. For the special case of GJR(1,1), Ling and McAleer [23] showed that the regularity condition for the existence of the second moment under symmetry of $\eta_{t}$ is 


$$
\alpha+\beta+\frac{1}{2}<1
$$

and the condition for the existence of the fourth moment under normality of $\eta_{t}$ is

$$
\beta^{2}+2 \alpha \beta+3 \alpha+\beta \gamma+3 \alpha \beta+\frac{3}{2} \gamma^{2}<1
$$

while McAleer et al. [27] showed that the weaker log-moment condition for GJR(1,1) was given by

$$
E\left(\ln \left[\left(\alpha+\gamma I\left(\eta_{t}\right)\right) \eta_{t}^{2}+\beta\right]\right)<0
$$

which involves the expectation of a function of a random variable and unknown parameters.

An alternative model to capture asymmetric behavior in the conditional variance is the Exponential GARCH $(\operatorname{EGARCH}(1,1))$ model of Nelson [20], namely:

$$
\log h_{t}=\omega+\alpha\left|\eta_{t-1}\right|+\gamma \eta_{t-1}+\beta \log h_{t-1}, \quad|\beta|<1
$$

where the parameters $\alpha, \beta$ and $\gamma$ have different interpretations from those in the GARCH(1,1) and GJR(1,1) models.

As noted in McAleer et al. [27], there are some important differences between EGARCH and the previous two models, as follows: (i) EGARCH is a model of the logarithm of the conditional variance, which implies that no restrictions on the parameters are required to ensure $h_{t}>0$; (ii) Nelson [20] showed that $|\beta|<1$ ensures stationarity and ergodicity for $\operatorname{EGARCH}(1,1)$; (iii) Shephard [39] observed that $|\beta|<1$ is likely to be a sufficient condition for consistency of QMLE for EGARCH(1,1); (iv) as the conditional (or standardized) shocks appear in equation (4), $|\beta|<1$ would seem to be a sufficient condition for the existence of moments; and (v) in addition to being a sufficient condition for consistency, $|\beta|<1$ is also likely to be sufficient for asymptotic normality of the QMLE of EGARCH(1,1). 
Furthermore, EGARCH captures asymmetries differently from GJR. The parameters $\alpha$ and $\gamma$ in $\operatorname{EGARCH}(1,1)$ represent the magnitude (or size) and sign effects of the conditional (or standardized) shocks, respectively, on the conditional variance, whereas $\alpha$ and $\alpha+\gamma$ represent the effects of positive and negative shocks, respectively, on the conditional variance in $\operatorname{GJR}(1,1)$.

\section{Empirical Results}

\subsection{Minimum LM unit root test with one and two breaks}

The empirical results for the unit root tests, which are given in Table 2, generally indicate that the ADF test does not reject the null hypothesis of a unit root. However, MAP, Urea, and ROCK reject the null hypothesis at the $1 \%$ significance level, which is consistent with no unit root for these prices, as shown in Table 3, for the minimum LM unit root test with two breaks (see Lee and Strazicich [1]). The price series for ammonia are tested using the minimum LM test unit root with one breakpoint as two breakpoints were not detected.

\subsection{Granger Causality Test}

As the results for testing the stationarity of the seven series indicate that all are stationary, we examine the relationships between the six fertilizer prices and the price of crude oil using the Granger Causality test [40]. From Table 4, the crude oil price (given as Poil) is found to Granger-cause five fertilizer prices, namely MAP, urea, ammonia, ACID, and MOP, in each period, which indicates that oil prices can be used to predict these five fertilizer prices. However, the crude oil price does not Granger-cause the ROCK price at the 5\% level of significance, which may not be so surprising as ROCK is a raw material used to produce phostate fertilizer, and hence does not use considerable energy. Thus, the oil price is not able to predict the ROCK price. 


\subsection{ARDL and Volatility Models for Crude Oil and Global Fertilizer Prices}

The estimates of equation (1) for the MAP, urea, ammonia, ROCK, ACID and MOP prices are given in Tables 6-11. Table 6 reports the estimates of crude oil price on MAP price for different periods. The coefficients of prices represent the change in the MAP price due to the change in the crude oil price. Similarly, the estimates of the price change for urea, ammonia, ACID, and MOP prices are reported in Tables 7-11, respectively. Owing to an insignificant causal relationship between ROCK price and crude oil price, we only estimate the volatility models for the ROCK price.

Several findings are given, as follows. The first main result is that the change in the lag one or two periods in the crude oil price has significant impacts on the prices of MAP, urea, ammonia, ACID, and MOP for the three time periods. For each fertilizer price, the effect of the crude oil price in the second and third periods is maintained at a higher level than in the first period. These empirical outcomes indicate that crude oil price and MAP, urea, ammonia, ACID, and MOP prices are more strongly related when the crude oil price is at a higher level, which is consistent with the observations in Figures 1 and 2.

Another important issue to investigate is the effect on the five fertilizer prices due to a $1 \%$ change in the crude oil price, as implied in Tables $6-11$. The percentage changes in fertilizer prices due to a $1 \%$ change in the crude oil price provide vital information concerning the sensitivity of each fertilizer price to changes in the oil price. For example, as shown in Table 12, the impact of the oil price on the MAP price is $1.252 \%$ in the first period, $4.912 \%$ in the second period, and $6.416 \%$ in the third period. Similar qualitative results are obtained for the effects of crude oil prices on the remaining four fertilizer prices.

The percentage changes in the five fertilizer prices due to a $1 \%$ change in the 
lagged values of crude oil price are positive in the second and third periods, but not in the first period, as the crude oil price has reached extremely high levels in the second and third periods. The oil price change is found to affect the price of fertilizer commodities through sharp increases in the prices of various energy-intensive inputs, including raw materials and fuel. This marked increase in the oil price is likely to have increased production costs. Consequently, the sensitivity of the five fertilizer prices to increases in the crude oil price become statistically significant when the crude oil price remains at a high level.

\subsection{Alternative Volatility Models for Crude Oil and Six Global Fertilizer Prices}

In order to investigate global fertilizer price volatility, an appropriate time series model needs to be determined that satisfies the appropriate regularity conditions. The first task is to determine the processes for the mean equation. We choose the ARMA processes with the smallest Schwarz Bayesian Information Criterion (BIC) value for the seven series in each period. The p-values of the Ljung-Box Q statistics of the residuals from the fitted models indicate that there is no autocorrelation at the $5 \%$ significance level. The specifications of the conditional mean and variance equations for the seven series are given in Table 5-11, respectively.

The appropriate volatility models for each of the six fertilizer prices and crude oil price are chosen on the basis of BIC and the regularity conditions, namely for the higher-order moments to exist, and hence for the asymptotic properties of consistency and asymptotic normality of the QMLE. The QMLE will be consistent and asymptotically normal when the weak log-moment condition is satisfied.

The empirical estimates for the alternative volatility models for the seven price series are given in Tables 5-11 for the three different time periods (that is, with. one or two structural breakpoints). Suitable models for Poil are $\operatorname{GJR}(1,1)$ for the first two 
periods, and $\operatorname{GARCH}(1,1)$ for the third period, as shown in Table 5. Periods 1 and 2 have asymmetric effects (with $\gamma>0$ in the GJR $(1,1)$ model). The short run persistence of shocks in periods 1,2 , and 3 are $0.079,0.311$ and 0.282 , respectively, while the long run persistence of shocks in period 3 is 0.768 , which is higher than in periods 1 and 2 of 0.314 , and 0.519 , respectively. These empirical outcomes indicate that a higher peak in the crude oil price is associated with greater volatility, which can be difficult to control. Thus, it is important for energy policy to understand the relationship between the prices and volatility of crude oil and global fertilizer prices.

For the MAP price series, a suitable model in three periods is $\operatorname{GARCH}(1,1)$, as shown in Table 6 . The estimated coefficients satisfy the sufficient conditions for the conditional variance to be positive $\left(h_{t} \geq 0\right)$. The short run persistence of shocks for MAP in periods 1,2 and 3 is $0.108,0.288$ and 0.387 , respectively, while long run persistence is $0.385,0.554$ and 0.856 , respectively. Thus, MAP has the greatest long run persistence of shocks in the third period. As compared with both the short and long run persistence of the MAP and crude oil price, both price series have similar volatility effects in the three periods. In other words, both the level and volatility of MAP prices seem to be highly correlated with the crude oil price.

Table 7 shows that the GARCH $(1,1)$ model is the appropriate model for the three periods for the Urea series. The estimates show that the weak log-moment condition is satisfied, so that the QMLE in the three periods for Urea are consistent and asymptotically normal. The short run persistence of shocks for Urea in periods 1, 2 and 3 is $0.059,0.364$ and 0.312 , respectively, and the long run persistence of shocks in periods 1,2 and 3 is $0.331,0.643$ and 0.907 , respectively. The long run persistence of shocks in period 3 is greater than in the other two periods, which is similar to the case of the crude oil and MAP prices.

The appropriate model for the Ammonia series in the first and second periods is 
GARCH( $(1,1)$, as shown in Table 8 . The short run persistence of shocks in periods 1 and 2 is 0.066 and 0.387 , respectively, while the long run persistence of shocks in periods 1 and 2 is 0.356 and 0.899 , respectively. The long run persistence of shocks in the second period is greater than its counterpart in period 1.

Appropriate volatility models for Rock, Acid, and MOP prices for the three different time periods are shown in Tables 9-11. For the Rock price series, the suitable model in the three time periods is $\operatorname{GARCH}(1,1)$, as shown in Table 9. For the Acid price series, as shown in Table 10, the best model in the three periods is $\operatorname{GARCH}(1,1)$. For the MOP price series, as shown in Table 11, the best model for all three time periods is $\operatorname{GARCH}(1,1)$.

The empirical results show that the long run persistence of shocks in periods 1,2 and 3 is $0.436,0.621$ and 0.811 , respectively, for the Rock price, so that the Rock price in period 3 has the greatest long run persistence of shocks. For Acid prices, the long run persistence of shocks in periods 1,2 and 3 is $0.316,0.430$ and 0.694 , respectively, so that the long run persistence in period 3 is the greatest. With regard to MOP prices, the long run persistence of shocks in the three periods is $0.230,0.672$ and 0.885 , respectively, so that the third period again has the greatest long run persistence of shocks. Moreover, these price series behave in a similar manner to that of the crude oil price.

\section{Concluding Remarks}

The main purpose of the paper was to evaluate empirically the effect of crude oil price on global fertilizer prices, both in the mean and volatility. Weekly data for 2003-2008 were used in the empirical analysis. First, three time periods with two structural breakpoints were determined endogenously for six global fertilizer prices and crude oil price, using the Lee and Strazicich (2003) approach. Second, with regard to 
the relationships between the crude oil price and six global fertilizer prices, the Granger causality test showed that most global fertilizer prices are influenced by the crude oil price. The empirical results from the ARDL model showed that the percentage changes in five fertilizer prices (namely MAP, Urea, Ammonia, ACID, MOP) due to a $1 \%$ change in the crude oil price are relatively larger, and also statistically significant, in the second and third periods, which suggests that the oil price is an important factor in production costs for fertilizer commodities. Consequently, the sensitivity of the five fertilizer prices to the oil price increased, and became statistically significant. This also explains why global fertilizer prices reached a peak in 2008, as the crude oil price reached a high level in 2008.

An empirically adequate model of volatility of the six global fertilizer prices was determined by checking the regularity conditions of the estimated models. The symmetric and asymmetric univariate conditional volatility models, including the widely used GARCH, GJR and EGARCH models, were estimated and selected on the basis of the BIC criterion and the regularity conditions for the QMLE to be consistent and asymptotically normal. This is important for the empirical analysis, otherwise the empirical results would have no statistical foundation.

The contribution of shocks to the long run persistence of crude oil prices during the third period was found to be greater than during the first and second periods. This would suggest that the volatility in crude oil prices has recently increased in both strength and frequency. Therefore, the strength and frequency of global fertilizer prices has increased gradually over time. As the volatility in global fertilizer prices has increased, vital energy prices and global agricultural production are likely to be affected significantly. This may lead to future instability in agricultural food prices. These empirical findings are crucial for determining sensible energy policy in order to 
understand the directional relationship between the prices and volatility of crude oil and global fertilizer prices. 


\section{References}

[1] Lee J, Strazicich MC. Minimum Lagrange Multiplier Unit Root Test with Two Structural Breaks. Rev Econ Stat 2003; 85: 1082-1089.

[2] Dickey DA, Fuller WA. Distribution of the Estimators for Autoregressive Time Series with a Unit Root. J Am Stat Ass 1979; 74: 427-431.

[3] Dickey DA, Fuller WA. Likelihood Ratio Statistics for Autoregressive Time Series with a Unit Root, Econometrica 1981; 49: 1057-1072.

[4] Said S, Dickey D. Testing for unit roots in autoregressive moving average models with unknown order. Biometrika 1984; 71: 599-607.

[5] Phillips PCB, Perron P. Testing for a unit root in time series regression. Biometrika $1988 ; 75: 335-346$.

[6] Nelson CR, Plosser CI. Trends and random walks In Macroeconomic Time Series. J Mon Econ 1982; 10: 139-162.

[7] Perron P. The Great Crash, the Oil Price Shock and the Unit Root Hypothesis. Econometrica 1989; 57: 1361-1401.

[8] Banerjee A, Lumsdaine RL, Stock JH. Recursive and Sequential Tests for a Unit Root: Theory and International Evidence. J Bus Ec Stat 1992; 10: 271-287.

[9] Zivot E, Andrews DWK. Further Evidence on Great Cash, the Oil Price Shock and the Unit Root Hypothesis. J Bus Ec Stat 1992; 10: 251-270.

[10] Lumsdaine R, Papell D.(1997) Multiple Trend Breaks and the Unit Root Hypothesis. Rev Econ Stat 1997; 79: 212-218.

[11] Jones CT. A single-equation study of U.S. petroleum consumption: the role of model specification. South Econ J 1993; 59(4): 687-700.

[12] Benten J, Engsted T. A revival of the autoregressive distributed lag model in estimating energy demand relationships. Energy 2001; 26:45-55. 
[13] Dimitropoulos J, Hunt LC, Judge G. Estimating underlying energy demand trends using UK annual data. App Ec Lett 2005; 12: 239-244.

[14] Hunt LC, Ninomiya Y. Primary energy demand in Japan: an empirical analysis of long-term trends and future $\mathrm{CO}_{2}$ emissions. Energy Policy 2005; 33(11): 1409-1424.

[15] Hunt LC, Judge G, Ninomiya Y. Underlying trends and seasonality in UK energy demand: a sectoral analysis. Energ Ec 2003; 25(1) 93-118.

[16] Hendry DF. Dynamic Econometrics: Advanced Text in Econometrics. Oxford: 1995; Oxford University Press.

[17] Engle RF. Autoregressive Conditional Heteroskedasticity with Estimates of the Variance of United Kingdom Inflation. Econometrica 1982; 50: 987-1007.

[18] Bollerslev T. Generalized Autoregressive Conditional Heteroscedasticity. J Econometrics 1986; 31: 307-327.

[19] Glosten L, Jagannathan R, Runkle D. On the Relation Between the Expected Value and Volatility of Nominal Excess Return on Stocks. J Finance 1992; 46: 1779-1801.

[20] Nelson DB. Conditional Heteroscedasticity in Asset Returns: A New Approach. Econometrica 1991; 59: 347-370.

[21] Ling S, Li WK. On Fractionally Integrated Autoregressive Moving-Average Models with Conditional Heteroskedasticity. J Am Stat Ass 1997; 92: 1184-1194.

[22] Ling S, McAleer M. Stationarity and the Existence of Moments of a Family of GARCH Processes. J Econometrics 2002a; 106: 109-117.

[23] Ling S, McAleer M. Necessary and Sufficient Moment Conditions for the GARCH(r,s) and Asymmetric Power GARCH(r,s) Models. Econometric Theory 2002b; 18: 722-729. 
[24] Ling S, McAleer M. Asymptotic Theory for a Vector ARMA-GARCH Model. Econometric Theory 2003a; 19: 278-308.

[25] Ling S, McAleer M. On Adaptive Estimation in Nonstationary ARMA Models with GARCH Errors. Ann Stat 2003b; 31: 642-674.

[26] McAleer M. Automated Inference and Learning in Modeling Finanical Volatility. Econometric Theory 2005; 21: 232-261.

[27] McAleer M, Chan F, Marinova D. An Econometric Analysis of Asymmetric Volatility: Theory and Application to Patents. J Econometrics 2007; 139: 259-284.

[28] Chan F, Marinova D, McAleer M. Rolling Regressions and Conditional Correlations of Foreign Patents in the USA. Envi Mod Soft 2005a; 20: 1413-1422.

[29] Chan F, Marinova D, McAleer M. Modelling Thresholds and Volatility in US Ecological Patents. Env Mod Soft 2005b; 20: 1369-1378.

[30] Marinova D, McAleer M. Modelling Trends and Volatility in Ecological Patents in the USA. Env Mod Soft 2003; 18: 195-203.

[31] Hoti S, McAleer M, Pauwels L. Modelling Environmental Risk. Env Mod Soft 2005; 20: 1289-1298.

[32] McAleer M, Chan F. Modelling Trends and Volatility in Atmospheric Carbon Dioxide Concentrations, Env Mod Soft 2006; 20: 1273-1279.

[33] Nelson DB. Stationarity and Persistence in the GARCH(1,1) Model. Econometric Theory 1990; 6: 318-334.

[34] Bougerol P, Picard N. Stationarity of GARCH Processes and of Some Non-Negative Time Series. J Econometrics 1992; 52: 115-127.

[35] Elie L, Jeantheau T. Consistency in Heteroskedastic Models. Comptes Rendus de l’Académie des Sciences Série I 1995; 320: 1255-1258 (in French).

[36] Jeantheau T. Strong Consistency of Estimators for Multivariate ARCH Models. Econometric Theory 1998; 14: 70-86. 
[37] Lee SW, Hansen BE. Asymptotic Theory for the GARCH(1,1) Quasi-Maximum Likelihood Estimator. Econometric Theory 1994; 10: 29-52.

[38] Boussama F. Asymptotic Normality for the Quasi-Maximum Likelihood Estimator of a GARCH Model. Comptes Rendus de l'Academie des Sciences Série I 2000; 331: 81-84 (in French).

[39] Shephard N. Statistical Aspects of ARCH and Stochastic Volatility. In Cox DR, Barndorff-Nielsen OE, Hinkley DV eds. Time Series Models in Econometrics, Finance, and Other Fields, London: Chapman and Hall; 1996, pp. 1-67.

[40] Granger CWJ. Investigation Causal Relations by Econometric Models and Cross-spectral Methods. Econometrica 1969; 37: 424-438. 


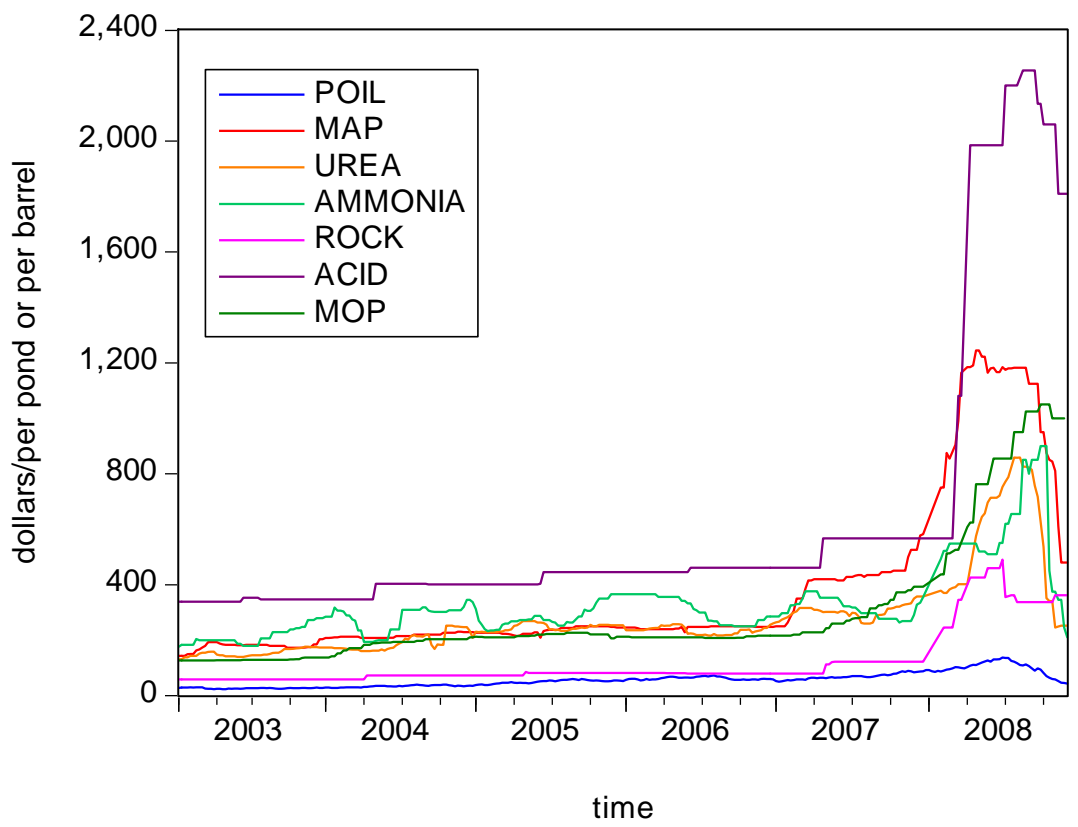

Figure 1. Price Trends for Global Fertilizers and Crude Oil, 2003-2008 


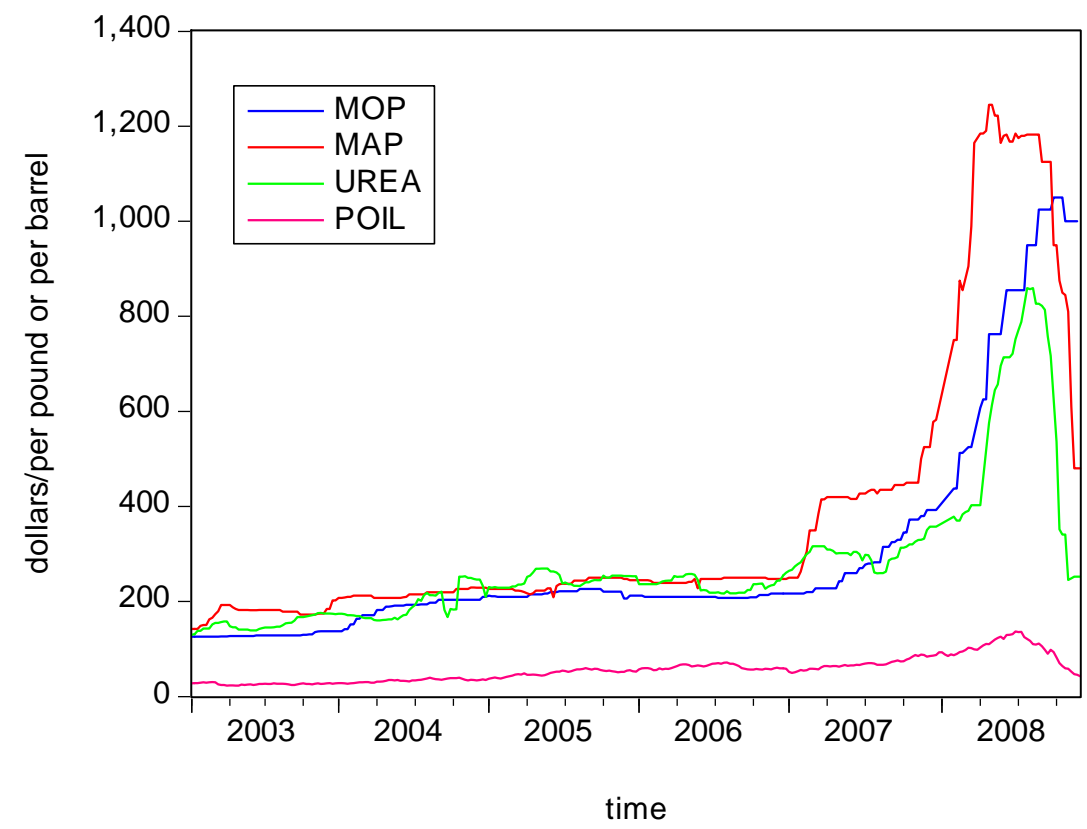

Figure 2. Higher Energy Use Fertilizer Prices and Crude Oil Price, 2003-2008 
Table 1. Descriptive Statistics of Seven Price Series

\begin{tabular}{|c|c|c|c|c|c|c|c|}
\hline Statistics & $\begin{array}{c}\text { MAP } \\
\text { (US\$ } \\
\text { /metric } \\
\text { ton) }\end{array}$ & $\begin{array}{c}\text { Urea } \\
\text { (US\$ } \\
\text { /metric } \\
\text { ton) }\end{array}$ & $\begin{array}{c}\text { Ammonia } \\
\text { (US\$ } \\
\text { /metric } \\
\text { ton) }\end{array}$ & $\begin{array}{c}\text { Acid } \\
\text { (US\$ } \\
\text { /metric } \\
\text { ton) }\end{array}$ & $\begin{array}{c}\text { Rock } \\
\text { (US\$ } \\
\text { /metric } \\
\text { ton) }\end{array}$ & $\begin{array}{c}\text { MOP } \\
\text { (US\$ } \\
\text { /metric } \\
\text { ton) }\end{array}$ & $\begin{array}{c}\text { Poil } \\
\text { (Price of } \\
\text { Oil. } \\
\text { US\$/Bale) }\end{array}$ \\
\hline Sample & 254 & 254 & 254 & 254 & 254 & 254 & 254 \\
\hline Mean & 258.07 & 225.80 & 280.72 & 428.30 & 78.46 & 206.18 & 48.29 \\
\hline Medium & 237 & 234.50 & 278.25 & 445.00 & 79.50 & 210.00 & 51.56 \\
\hline Maximum & 582.5 & 357.5 & 357.5 & 566.25 & 121.5 & 392.5 & 88.32 \\
\hline Minimum & 142.5 & 50.5 & 176 & 338.5 & 58 & 126 & 22.97 \\
\hline Std. Dev. & 89.39 & 55.51 & 53.89 & 70.01 & 18.97 & 57.95 & 17.23 \\
\hline
\end{tabular}


Table 2. Augmented Dickey-Fuller (ADF) Unit Root Tests

\begin{tabular}{lcccc}
\hline & \multicolumn{4}{c}{ ADF tests } \\
\cline { 2 - 5 } Series & With & With constant and & \multicolumn{2}{c}{ Critical values } \\
& constant & trend & With trend & With constant and \\
& & & & trend \\
Poil & $-1.326(1)$ & $-0.493(1)$ & $-3.457(1 \square)$ & $-3.995(1 \square)$ \\
MAP & $-2.154(9)$ & $-2.248(9)$ & $-2.873(5 \square)$ & $-3.428(5 \square)$ \\
Urea & $-2.439(3)$ & $-3.125(3)$ & $-2.573(10 \square)$ & $-3.137(10 \square)$ \\
Ammonia & $-1.089(9)$ & $-2.301(9)$ & & \\
Rock & $-2.372(0)$ & $-2.681(0)$ & & \\
Acid & $-2.179(0)$ & $-1.926(0)$ & & \\
MOP & $3.280(0)$ & $1.327(0)$ & & \\
\hline
\end{tabular}

Note: BIC is used to select the optimal lag length. The values in parentheses denote the number of lags. 
Table 3. LM Unit Root Tests with Two Breaks

\begin{tabular}{lcccc}
\hline Series & $\mathbf{L M}_{\boldsymbol{\tau}}$ & $\mathbf{k}$ & $\mathbf{T B 1}$ & $\mathbf{T B 2}$ \\
\hline Poil & $-6.017 * * *$ & 8 & 20071129 & 20080327 \\
MAP & $-8.239 * * *$ & 8 & 20071108 & 20080327 \\
Urea & $-8.264 * * *$ & 8 & 20071220 & 20080424 \\
Ammonia & $-5.775^{* *}$ & 7 & & 20080320 \\
Rock & $-7.926 * * *$ & 8 & 20070412 & 20080313 \\
Acid & $-15.920 * * *$ & 0 & 20071220 & 20080410 \\
MOP & $-9.549 * * *$ & 8 & 20071213 & 20080424 \\
\hline
\end{tabular}

Notes: The $1 \square, 5 \square$ and $10 \square$ critical values are $-5.823,-5.286$, and -4.989 , respectively

(see Lee and Strazicich, 2003). * ${ }^{* *}$ and $* * *$ denote significance at the $10 \square, 5 \square$

and $1 \square$ levels, respectively. 
Table 4. Granger Causality Test for Six Fertilizer Prices with Crude Oil Price

\begin{tabular}{llll}
\hline Dependent & \multicolumn{3}{c}{ Period } \\
\cline { 2 - 4 } Variable & Period 1 & Period 2 & Period 3 \\
\hline MAP & $4.030^{*}$ & $4.381^{*}$ & $4.958^{* *}$ \\
Urea & $4.099^{*}$ & & $5.195^{* *}$ \\
Ammonia & $3.429^{*}$ & $4.743^{* *}$ & \\
Rock & 0.336 & $3.576^{*}$ & 0.477 \\
Acid & $4.040^{*}$ & 1.086 & $3.622^{*}$ \\
MOP & $3.492^{*}$ & $3.378^{*}$ & $3.654^{*}$ \\
\hline
\end{tabular}

Note: The value in table 4 belongs to F-Statistics.

$*$ and $* *$ denote significance at the $5 \square$ and $1 \square$ levels, respectively. 
Table 5. Volatility in Crude Oil Prices

\begin{tabular}{|c|c|c|c|}
\hline Period & 2003/01/09-2007/11/22 & $2007 / 11 / 29-2008 / 03 / 20$ & 2008/03/27-2008/12/04 \\
\hline Series & $\operatorname{ARMA}(3,2)$ & $\operatorname{ARMA}(2,1)$ & $\operatorname{ARMA}(3,3)$ \\
\hline (Poil) & $\operatorname{GJR}(1,1)$ & $\operatorname{GJR}(1,1)$ & $\operatorname{GARCH}(1,1)$ \\
\hline \multicolumn{4}{|c|}{ Mean Equation } \\
\hline $\mathbf{R}(1)$ & 0.519 & 0.393 & 0.617 \\
\hline AK(1) & $(0.062)$ & $(0.016)$ & $(0.030)$ \\
\hline \multirow{2}{*}{$\operatorname{AR}(2)$} & 0.154 & 0.280 & 0.199 \\
\hline & $(0.007)$ & $(0.002)$ & $(0.010)$ \\
\hline \multirow{2}{*}{$\mathbf{A R}(3)$} & -0.181 & & 0.032 \\
\hline & $(0.061)$ & & $(0.087)$ \\
\hline \multirow{2}{*}{ MA(1) } & 0.473 & -0.268 & 0.323 \\
\hline & $(0.064)$ & $(0.065)$ & $(0.011)$ \\
\hline \multirow{2}{*}{ MA(2) } & -0.753 & & -0.293 \\
\hline & $(0.050)$ & & $(0.013)$ \\
\hline \multirow{2}{*}{ MA(3) } & & & 0.012 \\
\hline & & & $(0.077)$ \\
\hline \multicolumn{4}{|c|}{ Variance Equation } \\
\hline \multirow{2}{*}{$\omega$} & 0.527 & 0.372 & 0.007 \\
\hline & $(0.178)$ & $(0.164)$ & $(0.014)$ \\
\hline \multirow{2}{*}{$\alpha$} & 0.133 & 0.238 & 0.282 \\
\hline & $(0.034)$ & $(0.085)$ & $(0.031)$ \\
\hline \multirow{2}{*}{$\boldsymbol{\beta}$} & 0.235 & 0.207 & 0.485 \\
\hline & $(0.108)$ & $(0.199)$ & $(0.079)$ \\
\hline \multirow{2}{*}{$\gamma$} & -0.108 & 0.147 & \\
\hline & $(0.075)$ & $(0.096)$ & \\
\hline $\begin{array}{l}\text { Log } \\
\text { moment }\end{array}$ & -0.819 & -0.598 & -0.156 \\
\hline $\begin{array}{l}\text { Second } \\
\text { moment }\end{array}$ & 0.421 & 0.519 & 0.768 \\
\hline $\begin{array}{l}\text { Short run } \\
\text { persistence }\end{array}$ & 0.079 & 0.311 & 0.282 \\
\hline $\begin{array}{l}\text { Long run } \\
\text { persistence }\end{array}$ & 0.314 & 0.519 & 0.768 \\
\hline BIC & 2.491 & 3.814 & 4.601 \\
\hline
\end{tabular}

Note: Values in parentheses denote standard errors. 
Table 6. Mean and Volatility in MAP Prices

\begin{tabular}{|c|c|c|c|}
\hline Period & 2003/01/09-2007/11/01 & $2007 / 11 / 08-2008 / 03 / 20$ & 2008/03/27-2008/12/04 \\
\hline Series & $\operatorname{ARMA}(2,1)$ & $\operatorname{ARMA}(1,1)$ & $\operatorname{ARMA}(1,0)$ \\
\hline (MAP) & $\operatorname{GARCH}(1,1)$ & $\operatorname{GARCH}(1,1)$ & $\operatorname{GARCH}(1,1)$ \\
\hline \multicolumn{4}{|c|}{ Mean Equation } \\
\hline \multirow{2}{*}{$\operatorname{AR}(1)$} & 0.633 & 0.848 & 0.819 \\
\hline & $(0.212)$ & $(0.115)$ & $(0.056)$ \\
\hline \multirow{2}{*}{$\operatorname{AR}(2)$} & -0.284 & & \\
\hline & $(0.122)$ & & \\
\hline \multirow{2}{*}{ MA(1) } & 0.137 & -0.228 & \\
\hline & $(0.064)$ & $(0.092)$ & \\
\hline \multirow{2}{*}{ Oil Price(-1) } & 0.236 & 0.636 & 0.613 \\
\hline & $(0.107)$ & $(0.217)$ & $(0.225)$ \\
\hline \multirow{2}{*}{ Oil Price(-2) } & & & 0.280 \\
\hline & & & $(0.303)$ \\
\hline \multicolumn{4}{|c|}{ Variance Equation } \\
\hline \multirow{2}{*}{$\omega$} & 0.768 & 0.015 & 0.032 \\
\hline & $(0.363)$ & $(0.712)$ & $(0.700)$ \\
\hline \multirow{2}{*}{$\alpha$} & 0.108 & 0.288 & 0.387 \\
\hline & $(0.042)$ & $(0.104)$ & $(0.113)$ \\
\hline \multirow{2}{*}{$\boldsymbol{\beta}$} & 0.275 & 0.266 & 0.469 \\
\hline & $(0.057)$ & $(0.086)$ & $(0.150)$ \\
\hline \multicolumn{4}{|l|}{$\gamma$} \\
\hline Log moment & -0.478 & -0.373 & -0.105 \\
\hline $\begin{array}{l}\text { Second } \\
\text { moment }\end{array}$ & 0.385 & 0.554 & 0.856 \\
\hline $\begin{array}{l}\text { Short run } \\
\text { persistence }\end{array}$ & 0.108 & 0.288 & 0.387 \\
\hline $\begin{array}{l}\text { Long run } \\
\text { persistence }\end{array}$ & 0.385 & 0.554 & 0.856 \\
\hline BIC & 5.465 & 8.169 & 7.610 \\
\hline
\end{tabular}

Note: Values in parentheses denote standard errors. 
Table 7. Mean and Volatility in Urea Prices

\begin{tabular}{|c|c|c|c|}
\hline Period & 2003/01/09-2007/12/13 & $2007 / 12 / 20-2008 / 04 / 17$ & $2008 / 04 / 24-2008 / 12 / 04$ \\
\hline Series & $\operatorname{ARMA}(1,1)$ & $\operatorname{ARMA}(1,1)$ & $\operatorname{ARMA}(1,1)$ \\
\hline (Urea) & $\operatorname{GARCH}(1,1)$ & $\operatorname{GARCH}(1,1)$ & $\operatorname{GARCH}(1,1)$ \\
\hline \multicolumn{4}{|c|}{ Mean Equation } \\
\hline \multirow{2}{*}{$\operatorname{AR}(1)$} & 0.675 & 0.756 & 0.779 \\
\hline & $(0.018)$ & $(0.052)$ & $(0.047)$ \\
\hline \multirow{2}{*}{ MA(1) } & -0.238 & -0.183 & 0.050 \\
\hline & $(0.088)$ & $(0.086)$ & $(0.012)$ \\
\hline \multirow{2}{*}{ Oil Price(-1) } & 0.806 & 3.114 & 2.897 \\
\hline & $(0.294)$ & $(0.719)$ & $(0.225)$ \\
\hline \multirow{2}{*}{ Oil Price(-2) } & 0.531 & 1.958 & 1.493 \\
\hline & $(0.248)$ & $(0.735)$ & $(0.188)$ \\
\hline \multirow{2}{*}{ Oil Price(-3) } & & & 0.574 \\
\hline & & & $(0.163)$ \\
\hline \multicolumn{4}{|c|}{ Variance Equation } \\
\hline \multirow{2}{*}{$\omega$} & 0.452 & 0.647 & 0.094 \\
\hline & $(0.313)$ & $(0.609)$ & $(0.826)$ \\
\hline \multirow{2}{*}{$\alpha$} & 0.059 & 0.364 & 0.312 \\
\hline & $(0.023)$ & $(0.109)$ & $(0.107)$ \\
\hline \multirow{2}{*}{$\boldsymbol{\beta}$} & 0.272 & 0.279 & 0.595 \\
\hline & $(0.088)$ & $(0.133)$ & $(0.168)$ \\
\hline \multicolumn{4}{|l|}{$\gamma$} \\
\hline Log moment & -0.506 & -0.259 & -0.067 \\
\hline $\begin{array}{l}\text { Second } \\
\text { moment }\end{array}$ & 0.331 & 0.643 & 0.907 \\
\hline $\begin{array}{l}\text { Short run } \\
\text { persistence }\end{array}$ & 0.059 & 0.364 & 0.312 \\
\hline $\begin{array}{l}\text { Long run } \\
\text { persistence }\end{array}$ & 0.331 & 0.643 & 0.907 \\
\hline BIC & 6.485 & 6.853 & 6.305 \\
\hline
\end{tabular}

Note: Values in parentheses denote standard errors. 
Table 8. Mean and Volatility in Ammonia Prices

\begin{tabular}{|c|c|c|}
\hline Period & 2003/01/09-2008/03/13 & 2008/03/20-2008/12/04 \\
\hline Series & $\operatorname{ARMA}(2,1)$ & $\operatorname{ARMA}(1,0)$ \\
\hline (Ammonia) & $\operatorname{GARCH}(1,1)$ & $\operatorname{GARCH}(1,1)$ \\
\hline \multicolumn{3}{|c|}{ Mean Equation } \\
\hline $\mathrm{R}(1)$ & 0.883 & 0.788 \\
\hline AN(I) & $(0.022)$ & $(0.180)$ \\
\hline \multirow{2}{*}{$\operatorname{AR}(2)$} & -0.299 & \\
\hline & $(0.022)$ & \\
\hline \multirow{2}{*}{ MA(1) } & 0.216 & \\
\hline & $(0.040)$ & \\
\hline \multirow{2}{*}{ Oil Price(-1) } & 1.085 & 2.364 \\
\hline & $(0.318)$ & $(0.489)$ \\
\hline \multirow{2}{*}{ Oil Price(-2) } & 0.447 & 1.402 \\
\hline & $(0.212)$ & $(0.315)$ \\
\hline \multicolumn{3}{|c|}{ Variance Equation } \\
\hline \multirow{2}{*}{$\omega$} & 0.113 & 0.214 \\
\hline & (2.494) & $(1.130)$ \\
\hline \multirow{2}{*}{$\alpha$} & 0.066 & 0.387 \\
\hline & $(0.025)$ & $(0.112)$ \\
\hline \multirow{2}{*}{$\boldsymbol{\beta}$} & 0.290 & 0.512 \\
\hline & $(0.038)$ & $(0.245)$ \\
\hline \multicolumn{3}{|l|}{$\gamma$} \\
\hline Log moment & -0.472 & -0.174 \\
\hline Second moment & 0.356 & 0.899 \\
\hline Short run persistence & 0.066 & 0.387 \\
\hline Long run persistence & 0.356 & 0.899 \\
\hline BIC & 7.238 & 7.568 \\
\hline
\end{tabular}

Note: Values in parentheses denote standard errors. 
Table 9. Mean and Volatility in Rock Prices

\begin{tabular}{|c|c|c|c|}
\hline Period & 2003/01/09-2007/04/05 & $2007 / 04 / 12-2008 / 03 / 06$ & $2008 / 03 / 13-2008 / 12 / 04$ \\
\hline Series & $\operatorname{ARMA}(2,1)$ & $\operatorname{ARMA}(1,1)$ & $\operatorname{ARMA}(3,2)$ \\
\hline (Rock) & $\operatorname{GARCH}(1,1)$ & GARCH(1,1) & $\operatorname{GARCH}(1,1)$ \\
\hline \multicolumn{4}{|c|}{ Mean Equation } \\
\hline \multirow{2}{*}{$\operatorname{AR}(1)$} & 0.334 & 0.963 & 0.703 \\
\hline & $(0.061)$ & $(0.054)$ & $(0.263)$ \\
\hline \multirow{2}{*}{$\operatorname{AR}(2)$} & 0.248 & & -0.149 \\
\hline & $(0.009)$ & & $(0.107)$ \\
\hline \multirow{2}{*}{ MA(1) } & 0.371 & -0.223 & 0.279 \\
\hline & $(0.061)$ & $(0.027)$ & $(0.080)$ \\
\hline \multirow{2}{*}{ MA(2) } & & & 0.106 \\
\hline & & & $(0.051)$ \\
\hline \multicolumn{4}{|c|}{ Variance Equation } \\
\hline \multirow{2}{*}{$\omega$} & 0.005 & 0.121 & 0.160 \\
\hline & $(0.004)$ & $(0.164)$ & $(0.191)$ \\
\hline \multirow{2}{*}{$\alpha$} & 0.109 & 0.262 & 0.369 \\
\hline & $(0.022)$ & $(0.084)$ & $(0.095)$ \\
\hline \multirow{2}{*}{$\boldsymbol{\beta}$} & 0.327 & 0.359 & 0.442 \\
\hline & $(0.196)$ & $(0.105)$ & $(0.034)$ \\
\hline \multicolumn{4}{|l|}{$\gamma$} \\
\hline Log moment & -0.579 & -0.436 & -0.127 \\
\hline $\begin{array}{l}\text { Second } \\
\text { moment }\end{array}$ & 0.436 & 0.621 & 0.811 \\
\hline $\begin{array}{l}\text { Short run } \\
\text { persistence }\end{array}$ & 0.109 & 0.262 & 0.369 \\
\hline $\begin{array}{l}\text { Long run } \\
\text { persistence }\end{array}$ & 0.436 & 0.621 & 0.811 \\
\hline BIC & 1.751 & 2.611 & 2.558 \\
\hline
\end{tabular}

Note: Values in parentheses denote standard errors. 
Table 10. Mean and Volatility in Acid Prices

\begin{tabular}{|c|c|c|c|}
\hline Period & 2003/01/09-2007/12/10 & $2007 / 12 / 17-2008 / 03 / 31$ & 2008/04/07-2008/12/04 \\
\hline \multirow{2}{*}{ Series (Acid) } & $\operatorname{ARMA}(1.0)$ & $\operatorname{ARMA}(2,1)$ & $\operatorname{ARMA}(3,2)$ \\
\hline & $\operatorname{GARCH}(1,1)$ & $\operatorname{GARCH}(1,1)$ & $\operatorname{GARCH}(1,1)$ \\
\hline \multicolumn{4}{|c|}{ Mean Equation } \\
\hline \multirow{2}{*}{$\mathbf{A R}(\mathbf{1})$} & 0.648 & 0.695 & 0.793 \\
\hline & $(0.043)$ & $(0.340)$ & $(0.190)$ \\
\hline \multirow{2}{*}{ MA(1) } & & 0.113 & 0.101 \\
\hline & & $(0.052)$ & $(0.023)$ \\
\hline \multirow{2}{*}{ Oil Price(-1) } & 0.214 & 1.053 & 0.628 \\
\hline & $(0.103)$ & $(0.304)$ & $(0.274)$ \\
\hline \multirow{2}{*}{ Oil Price(-2) } & 0.131 & & 0.325 \\
\hline & $(0.062)$ & & $(0.112)$ \\
\hline \multicolumn{4}{|c|}{ Variance Equation } \\
\hline \multirow{2}{*}{$\omega$} & 0.401 & 0.038 & 0.329 \\
\hline & $(0.326)$ & $(0.550)$ & $(1.063)$ \\
\hline \multirow{2}{*}{$\alpha$} & 0.059 & 0.203 & 0.298 \\
\hline & $(0.016)$ & $(0.098)$ & $(0.107)$ \\
\hline \multirow{2}{*}{$\beta$} & 0.257 & 0.227 & 0.463 \\
\hline & $(0.113)$ & $(0.126)$ & $(0.176)$ \\
\hline \multicolumn{4}{|l|}{$\gamma$} \\
\hline Log moment & -0.574 & -0.323 & -0.176 \\
\hline $\begin{array}{l}\text { Second } \\
\text { moment }\end{array}$ & 0.316 & 0.430 & 0.694 \\
\hline $\begin{array}{l}\text { Short run } \\
\text { persistence }\end{array}$ & 0.059 & 0.203 & 0.298 \\
\hline $\begin{array}{l}\text { Long run } \\
\text { persistence }\end{array}$ & 0.316 & 0.430 & 0.694 \\
\hline BIC & 7.222 & 7.475 & 7.202 \\
\hline
\end{tabular}

Note: Values in parentheses denote standard errors. 
Table 11. Mean and Volatility in MOP Prices

\begin{tabular}{|c|c|c|c|}
\hline Period & 2003/01/09-2007/12/06 & $2007 / 12 / 13-2008 / 04 / 17$ & $2008 / 04 / 24-2008 / 12 / 04$ \\
\hline Series & $\operatorname{ARMA}(2,1)$ & $\operatorname{ARMA}(1,1)$ & $\operatorname{ARMA}(1,0)$ \\
\hline (MOP) & GARCH(1,1) & GARCH(1,1) & GARCH(1,1) \\
\hline \multicolumn{4}{|c|}{ Mean Equation } \\
\hline \multirow{2}{*}{$\mathbf{A R}(\mathbf{1})$} & 0.830 & 0.899 & 0.896 \\
\hline & $(0.133)$ & $(0.256)$ & $(0.101)$ \\
\hline \multirow{2}{*}{$\operatorname{AR}(2)$} & -0.245 & & \\
\hline & $(0.107)$ & & \\
\hline \multirow{2}{*}{ MA(1) } & -0.122 & -0.271 & \\
\hline & $(0.053)$ & $(0.129)$ & \\
\hline \multirow{2}{*}{ Oil Price(-1) } & 0.108 & 0.958 & 0.707 \\
\hline & $(0.036)$ & $(0.273)$ & $(0.234)$ \\
\hline \multirow{2}{*}{ Oil Price(-2) } & 0.062 & & 0.294 \\
\hline & $(0.020)$ & & $(0.151)$ \\
\hline \multicolumn{4}{|c|}{ Variance Equation } \\
\hline \multirow{2}{*}{$\omega$} & 0.027 & 0.602 & 0.330 \\
\hline & $(0.028)$ & $(0.476)$ & $(0.571)$ \\
\hline \multirow{2}{*}{$\alpha$} & 0.096 & 0.438 & 0.285 \\
\hline & $(0.032)$ & $(0.163)$ & $(0.116)$ \\
\hline \multirow{2}{*}{$\beta$} & 0.142 & 0.234 & 0.600 \\
\hline & $(0.014)$ & $(0.114)$ & $(0.266)$ \\
\hline \multicolumn{4}{|l|}{$\gamma$} \\
\hline Log moment & -0.738 & -0.365 & -0.101 \\
\hline $\begin{array}{l}\text { Second } \\
\text { moment }\end{array}$ & 0.238 & 0.672 & 0.885 \\
\hline $\begin{array}{l}\text { Short run } \\
\text { persistence }\end{array}$ & 0.096 & 0.438 & 0.285 \\
\hline $\begin{array}{l}\text { Long run } \\
\text { persistence }\end{array}$ & 0.238 & 0.672 & 0.885 \\
\hline BIC & 4.755 & 8.722 & 7.563 \\
\hline
\end{tabular}

Note: Values in parentheses denote standard errors. 
Table 12. The Elasticity of Fertilizer Price with Respect to Crude Oil Price

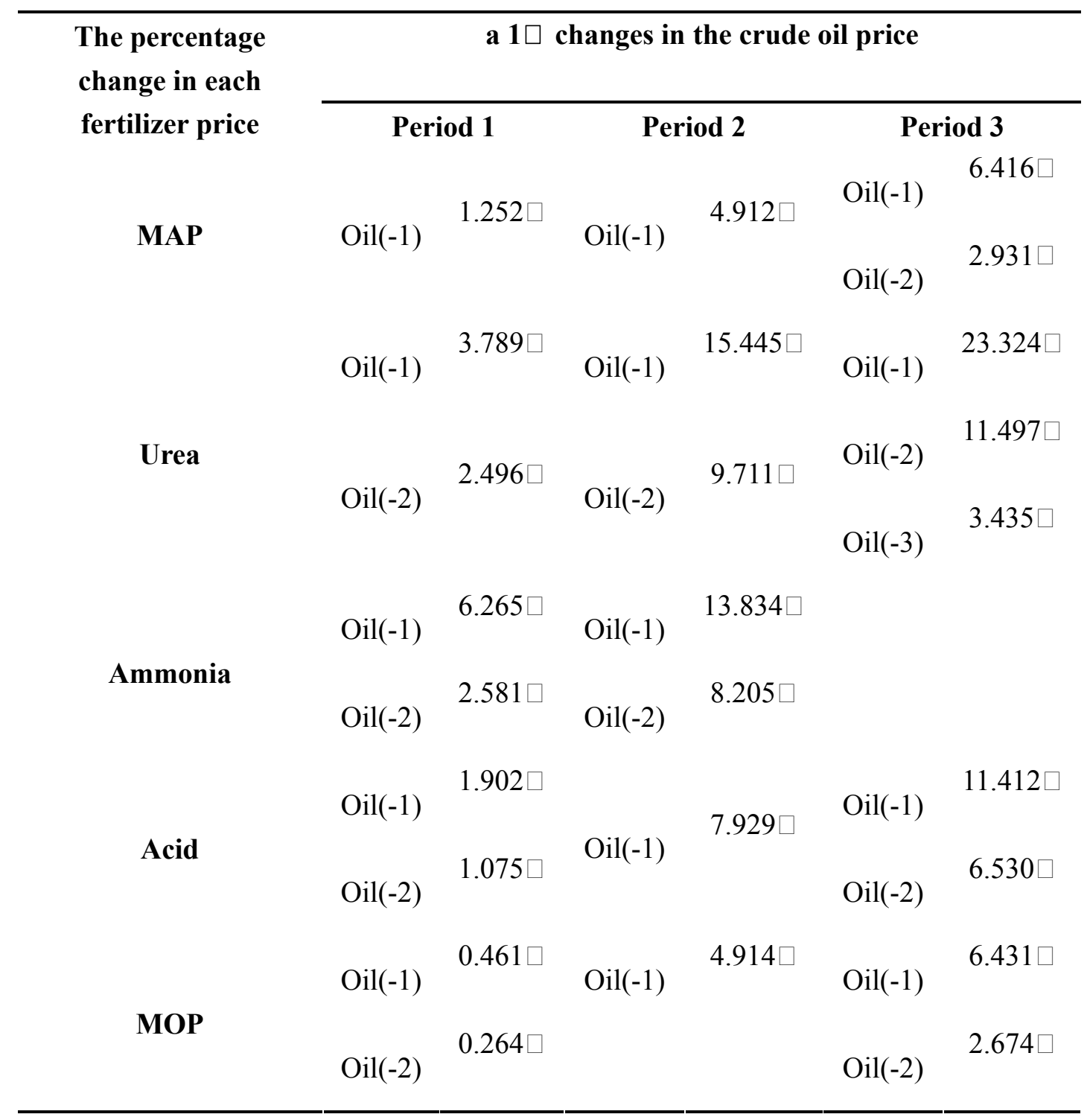

